\title{
Reduced miR-125a levels associated with poor survival of patients with hepatocellular cancer
}

\author{
GAIXIA LU $^{1 *}$, YUSHUI MA ${ }^{1 *}$, CHENGYOU JIA $^{1 *}$, HUIQIONG YANG $^{1}$, RUTING XIE $^{1}$, PEI LUO ${ }^{1}$, \\ LI CHAI $^{1}$, HAIDONG CAI ${ }^{1}$, MINGXIANG CAI ${ }^{1}$, ZHONGWEI LV ${ }^{1}$, XIANLING CONG $^{2}$ and DA FU ${ }^{1,3}$ \\ ${ }^{1}$ Department of Nuclear Medicine, Shanghai Tenth People's Hospital, Tongji University School of Medicine, Shanghai 200072; \\ ${ }^{2}$ Tissue Bank, China-Japan Union Hospital, Jilin University, Changchun, Jilin 130033; ${ }^{3}$ Research Center of Clinical Medicine, \\ Shanghai Tenth People's Hospital, Tongji University School of Medicine, Shanghai 200072, P.R. China
}

Received April 13, 2016; Accepted June 15, 2017

DOI: $10.3892 / \mathrm{ol} .2017 .6902$

\begin{abstract}
MicroRNAs (miRNAs) serve an important role in tumorigenesis and development. Although a low expression of miR-125a in hepatocellular carcinoma (HCC) has been reported, the clinical significance remains unknown. In the current study, the data of Gene Expression Omnibus datasets was analyzed and significantly low expression of miR-125a in HCC was verified. Furthermore, the expression and clinical significance of miR-125a was investigated in 27 normal liver and 98 HCC tissue samples using reverse transcription-quantitative polymerase chain reaction analysis. The results demonstrated that the level of miR-125a expression was lower in HCC biopsies compared with that in normal liver tissues. Survival analysis established that miR-125a expression was negatively associated with the prognosis of HCC. Multivariate survival analysis demonstrated that patients with HCC with lowmiR-125a and Ki67-positive expression have shorter overall, and disease-free survival times. Altogether, the results of the current study provide the first evidence that reducedmiR-125a expression is associated with HCC progression and poor prognosis in patients, suggesting that miR-125a may have potential prognostic value as a tumor biomarker for patients with HCC.
\end{abstract}

Correspondence to: Professor $\mathrm{Da} \mathrm{Fu}$, Department of Nuclear Medicine, Shanghai Tenth People's Hospital, Tongji University School of Medicine, 301 Yangchang Road, Shanghai 200072, P.R. China

E-mail: fu800da900@163.com

Professor Xianling Cong, Tissue Bank, China-Japan Union Hospital, Jilin University, 126 Xiantai Street, Changchun, Jilin 130033, P.R. China

E-mail: congx1888@hotmail.com

*Contributed equally

Key words: microR-125a, hepatocellular carcinoma, overall survival, disease-free survival, risk factor

\section{Introduction}

Liver cancer is the fifth most prevalent cancer and the third leading cause of cancer-associated mortality, immediately following lung, and colorectal cancer worldwide (1). Hepatocellular carcinoma (HCC) is the most common form of adult liver cancer, representing $>90 \%$ of all cases of primary liver cancer (2). Great advances in the treatment of liver cancer, relapse and metastasis are frequently observed in the clinic, and the poor 5-year survival rate is attributed to late diagnosis, resistance to treatment, tumor recurrence and metastasis, hence stressing the importance of novel diagnostics and therapeutics (3). It is also necessary to identify biological markers that can be used to screen high-risk patients in order to obtain earlier HCC diagnosis, earlier intervention and increase the likelihood of successful treatment (4).

Regarding diagnosis biomarkers, microRNAs (miRNAs) have become a hot topic in the field of cancer biological research. miRNAs are non-coding RNA molecules of 21-24 nucleotides that regulate the expression of target genes in a post-transcriptional manner. Evidence indicates that miRNA serve essential roles in embryogenesis, cell differentiation and the pathogenesis of various human diseases, including cancer $(5,6)$. Furthermore, their expression levels have been identified to be dysregulated in numerous cancer types some of which have been directly implicated in carcinogenetic mechanisms, and several altered expressions of miRNAs have previously been described in rat and human HCC (7-9).

Several previous studies have revealed that the expression of miRNAs is dysregulated in human HCC in comparison with matched non-neoplastic tissue (10). miR-221, miR-19b and miR-224 expression levels were increased in hepatitis $\mathrm{C}$ virus recurrence samples, while miR-129, and miR-335 were decreased compared with normal liver tissue $(5,11)$. From the comprehensive miRNAs expression analysis of HCC tissues paired with adjacent non-cancerous hepatic tissues, miR-221 has been identified to repress endogenous histone deacetylase 6 expression in HCC cells (10). The overexpression of miR-19b was significantly correlated with better overall and disease-free survival rates for patients with HCC presenting with vascular invasion or multifocal disease following curative surgery (11). In addition, previous results demonstrated 
that miR-129 and miR-335 can suppress tumorigenesis, and progression, defining them as potential treatment targets for HCC (5).

miR-125a has been previously reported to be altered in various human cancer types $(12,13)$. However, little is known about the association between miR-125a expression and the survival of patients with HCC. In the present study, in silico analysis of differentially expressed miRNAs was first performed on patients with HCC vs. controls using the Gene Expression Omnibus (GEO) database data. Subsequently, miR-125a expression was assessed in 27 normal liver and 98 HCC tissue samples using reverse transcription-quantitative polymerase chain reaction (RT-qPCR). The aim of the current study was to evaluate the efficacy of miR-125a as a prognostic marker for patients with HCC.

\section{Materials and methods}

miRNA expression of HCC from GEO database. In order to investigate the association between miRNAs and the development of liver cancer, the raw data GSE31383 from the GEO database was downloaded (http://www.ncbi.nlm.nih.gov/geo/). This dataset includes miRNA expression data from 10 healthy liver and 9 HCC. In addition, GSE20594 (including 10 normal controls and $89 \mathrm{HCC}$ ) and GSE36915 (including 21 normal controls and $69 \mathrm{HCC}$ ) were downloaded to identify differentially expressed miRNAs for HCC.

Tissue samples. Liver tissue samples from 27 healthy liver and tumor tissues from 98 HCC patients (Table I), who underwent surgical resection between January 2008 and December 2012, were collected from the Tissue Bank, Jilin University (Changchun, China). Fresh tissue samples were frozen within the 30 min after surgery and stored in liquid nitrogen until use. The inclusion criteria was $\leq 75$ years of age with histologically proven $\mathrm{CRC}$, no severe major organ dysfunction, World Health Organization (WHO) (14) performance status of 0 or 1 and no prior cancer chemotherapy. The exclusion criteria included an age of $\geq 76$ years, severe major organ dysfunction, WHO performance status of $>1$ or prior cancer chemotherapy. Two experienced pathologists confirmed HCC diagnosis independently according to the WHO criteria. The present study was approved by the Ethics Committee of Shanghai Tenth People's Hospital, Tongji University School of Medicine (SHSY-IEC-pap-15-18; Shanghai, China) and the Ethics Committee of Jilin University (20151101). Patients and/or their legal surrogates provided written informed consent to the surgical procedures, and participation of the current study by donating tissue specimens.

Collection of patients' clinical and follow-up data. Clinical information was recorded including the patient's characteristics (gender, age, drinking status), tumor characteristics [number of lesions, invasion to tumor capsule, tumor differentiation, Ki67 expression, tumor node metastasis (TNM) stage, tumor capsule, tumor embolus and diameter; Table I], overall survival time (OS), disease-free survival time (DFS) and chemotherapy status. The last follow-up was performed on July 30th 2015 by direct correspondence or phone interview. The occasion of mortality or tumor relapse was verified by patients or their relatives or from their medical records or the social security records. OS was analyzed for the months from the date of diagnosis to the time of mortality, regardless of the cause. DFS was defined as the period from the initial date of diagnosis to the time of tumor progression by computed tomography scan or to the time of mortality due to the disease.

RNA isolation and RT-qPCR. Total RNA from HCC and normal tissues was isolated using TRIzol reagent (Invitrogen; Thermo Fisher Scientific, Inc., Waltham, MA, USA) according to the manufacturer's protocol. RNA concentration was measured using NanoDrop ND-1000 (Thermo Fisher Scientific, Inc.) and the quality was assessed using electrophoresis with $1.5 \%$ denaturing agarose gels. TaqMan probe-based qPCR was performed using a commercial kit (Applied Biosystems; Thermo Fisher Scientific, Inc.) according to the manufacturer's protocol. RT was performed using a miR-125a-specific primer and ABI's TaqMan MicroRNA Reverse Transcription kit (Applied Biosystems; Thermo Fisher Scientific, Inc.). miR-125a expression level was detected using a Taqman MicroRNA assay (Applied Biosystems; Thermo Fisher Scientific, Inc.).Reverse transcriptase reactions were performed using avian myeloblastosis virus reverse transcriptase (Takara Biotechnology Co., Ltd., Dalian, China) and qPCR was performed using a standard TaqMan PCR kit protocol with the Applied Biosystems 7900 HT Sequence Detection system. U6 was used as the internal control. The RT-qPCR thermocycling conditions were as follows: $94^{\circ} \mathrm{C}$ for $30 \mathrm{sec}$ (initial denaturation), $94^{\circ} \mathrm{C}$ for $5 \mathrm{sec}$ (denaturation) and $55^{\circ} \mathrm{C}$ for $30 \mathrm{sec}$ (annealing), for 40 cycles. U6 expression was used as the internal control. The following primers were used: miR-125a forward, 5'-GGT AAGTCACGCGGT-3' and reverse, 5'-CAGTGCGTCTCG TGGAGT-3'; U6 forward, 5'-CTGGTTAGTACTTGGACG GGAGAC-3' and reverse, 5'-GTGCAGGGTCCGAGGT-3'. miR-125a levels were quantified using the $2^{-\Delta \Delta C q}$ method (15).

Statistical analysis. Data are presented as the mean \pm standard deviation. Statistical significances between groups were determined using two-tailed Student's t-tests. The $\chi^{2}$ was used to compare the differences of categorical variables and the Student's t-test was used for comparison of differences between two groups. Kaplan-Meier survival curves and the log-rank test were used to analyze the OS or DFS of patients with HCC. Multivariate Cox proportional hazards regression models were performed to explore the prognostic value of multiple variables in HCC. All statistical analyses were performed using SPSS software (version 20.0; IBM Corp., Armonk, NY, USA). $\mathrm{P}<0.05$ was considered to indicate a statistically significant difference.

\section{Results}

Expression of miR-125a using the GEO database by clustering analysis. In order to identify the association between miRNA expression and the prognosis of patients with $\mathrm{HCC}$, in silico analysis using GEO database data (GSE31383) was performed first. There were 56 differentially expressed miRNAs identified between normal controls and HCC (Fig. 1A), which included specifically upregulated miRNAs (including miR-221, 
Table I. Univariate analysis of overall survival based on patients stratified by clinical characteristics.

\begin{tabular}{|c|c|c|c|c|c|c|}
\hline \multirow[b]{2}{*}{ Factor } & \multirow[b]{2}{*}{$\begin{array}{l}\text { No. of } \\
\text { patients }\end{array}$} & \multirow[b]{2}{*}{$\begin{array}{c}\text { miR-125a } \\
\text { expression }^{\mathrm{a}}\end{array}$} & \multirow[b]{2}{*}{ P-value } & \multicolumn{3}{|c|}{ Overall survival } \\
\hline & & & & $\begin{array}{l}\text { Months } \\
\text { (median) }\end{array}$ & $\begin{array}{l}95 \% \text { CI } \\
\text { (median) }\end{array}$ & $\begin{array}{c}\text { P-value } \\
\text { (Log-rank } \\
\text { test) }\end{array}$ \\
\hline \multicolumn{7}{|l|}{ Age (years) } \\
\hline$\geq 60$ & 52 & $1.62 \pm 0.35$ & \multirow[t]{2}{*}{0.822} & 81.19 & $67.14-95.24$ & \multirow[t]{2}{*}{0.468} \\
\hline$<60$ & 46 & $1.52 \pm 0.27$ & & 73.01 & $54.16-91.86$ & \\
\hline \multicolumn{7}{|l|}{ Gender } \\
\hline Male & 80 & $1.45 \pm 0.19$ & \multirow[t]{2}{*}{0.274} & 75.81 & $60.89-90.73$ & \multirow[t]{2}{*}{0.277} \\
\hline Female & 18 & $2.06 \pm 0.78$ & & 90.17 & $68.62-111.72$ & \\
\hline \multicolumn{7}{|l|}{ No. of lesions } \\
\hline Single & 63 & $1.79 \pm 0.37$ & \multirow[t]{2}{*}{0.431} & 88.44 & $76.56-100.33$ & \multirow[t]{2}{*}{0.003} \\
\hline Multiple & 35 & $1.44 \pm 0.27$ & & 51.13 & $30.31-71.96$ & \\
\hline \multicolumn{7}{|c|}{ Invasion to tumor capsule } \\
\hline Negative & 43 & $1.95 \pm 0.22$ & \multirow[t]{3}{*}{0.472} & 101.21 & 86.34-116.06 & \multirow[t]{3}{*}{0.019} \\
\hline Positive & 41 & $1.59 \pm 0.44$ & & 45.37 & $34.27-56.47$ & \\
\hline Unknown & 14 & $1.32 \pm 0.61$ & & 30.79 & $23.07-38.51$ & \\
\hline \multicolumn{7}{|c|}{ Tumor differentiation } \\
\hline Poorly & 18 & $1.72 \pm 0.28$ & \multirow[t]{4}{*}{0.391} & 40.21 & $35.48-51.93$ & \multirow[t]{4}{*}{0.062} \\
\hline Moderately & 62 & $1.06 \pm 0.43$ & & 49.36 & $41.25-58.76$ & \\
\hline Well & 8 & $1.03 \pm 0.41$ & & 45.45 & $32.47-55.61$ & \\
\hline Unknown & 10 & $1.55 \pm 0.62$ & & 20.26 & $16.74-32.93$ & \\
\hline \multicolumn{7}{|c|}{ Ki67 expression } \\
\hline Negative & 21 & $1.31 \pm 0.27$ & \multirow[t]{3}{*}{0.027} & 45.84 & $30.21-61.48$ & \multirow[t]{3}{*}{0.005} \\
\hline Positive & 35 & $0.60 \pm 0.17$ & & 55.52 & $37.04-74.01$ & \\
\hline Unknown & 42 & $0.71 \pm 0.31$ & & 80.15 & $66.89-93.39$ & \\
\hline \multicolumn{7}{|l|}{ TNM stage } \\
\hline I-II & 7 & $0.86 \pm 0.61$ & 0.836 & 51.17 & $34.98-67.35$ & 0.051 \\
\hline III-IV & 6 & $0.69 \pm 0.52$ & & 47.29 & $27.34-67.23$ & \\
\hline Unknown & 85 & $0.63 \pm 0.16$ & & 84.05 & $71.65-96.45$ & \\
\hline Drinking statu & & & & & & \\
\hline Negative & 72 & $1.80 \pm 0.26$ & 0.038 & 66.34 & $45.62-81.21$ & 0.413 \\
\hline Positive & 18 & $0.68 \pm 0.21$ & & 55.26 & $43.79-74.38$ & \\
\hline Unknown & 8 & $1.13 \pm 0.52$ & & 75.39 & $64.11-84.95$ & \\
\hline Tumor capsul & & & & & & \\
\hline Negative & 36 & $2.21 \pm 0.49$ & 0.125 & 45.69 & $33.94-57.47$ & 0.009 \\
\hline Positive & 48 & $1.45 \pm 0.19$ & & 93.57 & 76.06-111.09 & \\
\hline Unknown & 14 & $1.75 \pm 0.48$ & & 30.79 & $23.07-38.51$ & \\
\hline Tumor embol & & & & & & \\
\hline Negative & 64 & $2.21 \pm 0.58$ & 0.064 & 87.64 & $69.28-106.01$ & 0.008 \\
\hline Positive & 30 & $1.33 \pm 0.18$ & & 43.44 & $31.03-55.85$ & \\
\hline Unknown & 4 & $1.81 \pm 0.55$ & & 92.75 & $48.19-137.31$ & \\
\hline Diameter $(\mathrm{cm}$ & & & & & & \\
\hline$\geq 5$ & 58 & $1.25 \pm 0.23$ & 0.226 & 49.92 & $38.73-61.12$ & 0.149 \\
\hline$<5$ & 40 & $1.78 \pm 0.32$ & & 92.28 & $77.67-106.89$ & \\
\hline
\end{tabular}

${ }^{\text {aD }}$ ata presented as the mean \pm standard deviation. CI, confidence interval; TNM, tumor node metastasis; miR, microRNA.

miR-199a, let-7c/e, miR-10a, miR-21) that were reported previously in liver cancer (10-12).
The prognostic value of the novel miRNAs identified for patients with HCC was evaluated, one of which was miR-125a 

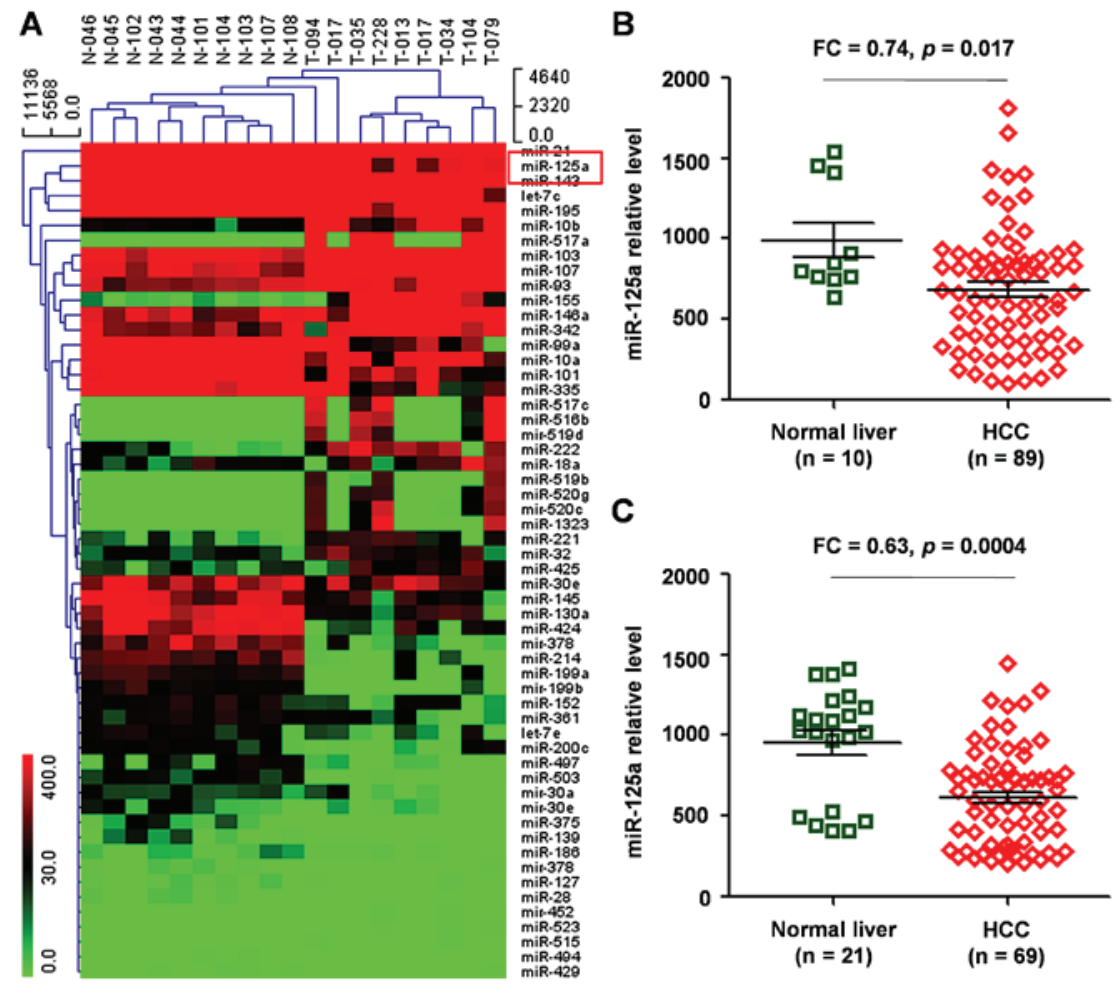

Figure 1. Analysis of miRNAs expression in patients with HCC was performed using GEO datasets, and MEV4.7.1 clustering software was used to analyze differential miRNAs. (A) Clustering analysis was performed using the MEV4.7.1 based on 56 dysregulated miRNAs using a FC $\geq 2$ and $\mathrm{P}<0.05$. miR-125a expression levels in HCC tissue vs. normal tissue were analyzedusing the GEO database, (B) GSE20594 and (C) GSE36915. FC, fold change; miR, microRNA; GEO, Gene Expression Omnibus; HCC, hepatocellular carcinoma.
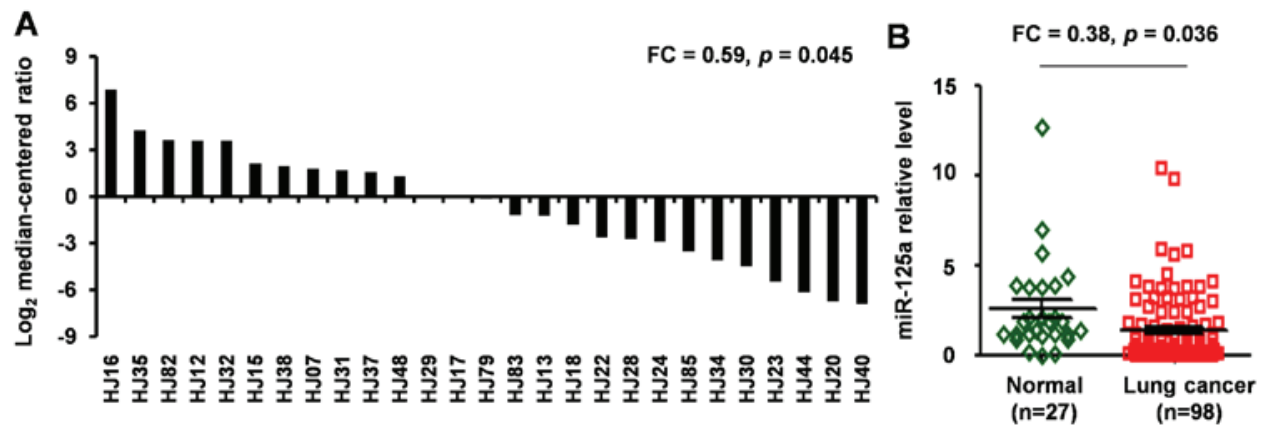

Figure 2. miR-125a expression in normal liver and HCC tissues. (A) miR-125a expression levels in HCC vs. paired adjacent non-tumor tissue (n=27). (B) miR-125a expression in HCC samples $(n=98)$ and adjacent non-tumor tissue $(n=27)$ were analyzed.FC, fold change; miR, microRNA.

that was identified to be significantly downregulated in HCC compared with normal liver tissue [fold change (FC), 0.64; $\mathrm{P}=0.039]$.

Two datasets (GSE20594 and GSE36915) of HCC vs. noncancerous tissue samples were used to validate the aforementioned findings, and it was demonstrated that miR-125a expression was significantly reduced in HCC compared with that in normal controls ( $\mathrm{P}=0.017$, Fig. $1 \mathrm{~B} ; \mathrm{P}=0.0004$, Fig. $1 \mathrm{C})$.

miR-125a expression in HCC and adjacent non-cancerous tissues. RT-qPCR was subsequently performed to quantify miR-125a levels in 98 HCC specimens and 27 non-cancerous tissues. The results of the qPCR analysis revealed that miR-125a levels were significantly lower in HCC tissues compared with that in 27 paired adjacent non-cancerous tissues (FC, 0.59;
$\mathrm{P}=0.045$; Fig. 2A). Furthermore, the level of miR-125a expression was significantly lower in all $98 \mathrm{HCC}$ biopsies compared with that in 27 adjacent non-cancerous tissues (FC, 0.38; $\mathrm{P}=0.036$; Fig. 2B).

Cox regression model analysis for prognosis based on various clinical characteristics in patients with HCC. In addition, the association between miR-125a expression in HCC samples and various clinical characteristics of patients was analyzed (including age, gender, number of lesions, invasion to tumor capsule, tumor differentiation, Ki67 expression, TNM stage, drinking status, tumor capsule, tumor embolus and diameter).

As presented in Table I, miR-125a expression was positively correlated with Ki67 expression and drinking status $(\mathrm{P}<0.05)$. However, no significant association was identified 
Table II. Cox regression model analysis for prognosis based on various clinical characteristics in patients with HCC.

\begin{tabular}{|c|c|c|c|c|c|c|}
\hline \multirow[b]{2}{*}{ Factor } & \multicolumn{3}{|c|}{ miR-125a univariate analysis } & \multicolumn{3}{|c|}{ miR-125a multivariate analysis } \\
\hline & HR & $95 \% \mathrm{CI}$ & P-value & HR & $95 \% \mathrm{CI}$ & $\mathrm{P}$-value \\
\hline Age (years) & 1.259 & $0.670-2.364$ & 0.474 & & & \\
\hline Gender & 0.600 & $0.235-1.536$ & 0.287 & & & \\
\hline No. of lesions & 2.291 & $1.326-3.678$ & 0.005 & & & \\
\hline Invasion to tumor capsule & 1.575 & $1.006-2.465$ & 0.047 & & & \\
\hline Tumor differentiation & 0.843 & $0.511-1.391$ & 0.504 & & & \\
\hline Ki67 expression & 1.745 & $1.183-2.577$ & 0.005 & 2.561 & $1.578-4.375$ & $<0.001$ \\
\hline TNM stage & 1.121 & $0.627-2.005$ & 0.701 & & & \\
\hline Drinking status & 1.145 & $0.572-2.292$ & 0.702 & & & \\
\hline Tumor capsule & 0.543 & $0.316-0.935$ & 0.027 & & & \\
\hline Tumor embolus & 1.569 & $0.976-2.522$ & 0.063 & & & \\
\hline Diameter & 1.575 & $0.840-2.951$ & 0.156 & & & \\
\hline $\operatorname{miR}-125 \mathrm{a}$ & 0.479 & $0.250-0.920$ & 0.027 & & & \\
\hline
\end{tabular}

HR, hazard ratio; CI, confidence interval; TNM, tumor node metastasis; miR, microRNA.

between $\mathrm{miR}-125 \mathrm{a}$ expression and other clinical characteristics, including age, gender, and tumor differentiation $(\mathrm{P}>0.05)$.

Association between clinical characteristics and $\mathrm{HCC}$ prognosis. In order to further analyze the prognostic value of other clinical factors, including age, gender, number of lesions, invasion to tumor capsule, tumor differentiation, Ki67 expression, drinking status, tumor capsule, tumor embolus, diameter and TNM stage, Kaplan-Meier survival curves were plotted, and comparisons were made using log-rank tests (Table I). It was demonstrated that the number of lesions was significantly associated with diminished $\mathrm{OS}(\mathrm{P}=0.003)$ in patients with $\mathrm{HCC}$. In addition, invasion to tumor capsule was significantly associated with decreased $\mathrm{OS}(\mathrm{P}=0.019)$. Similar results were obtained regarding Ki67 expression, tumor capsule, tumor embolus and $\mathrm{OS}(\mathrm{P}=0.005,0.009$ and 0.008 , respectively).

As presented in Table II, univariate analysis using the Cox regression model revealed that miR-125a expression levels [hazard ratio (HR), 0.479; confidence interval (CI), 0.25-0.92; $\mathrm{P}=0.027$ ], number of lesions (HR, 2.291; CI, 1.326-3.678; $\mathrm{P}=0.005)$, invasion to tumor capsule (HR, 1.575; CI, 1.006-2.465; $\mathrm{P}=0.047)$, Ki67 expression (HR, 1.745; CI, 1.183-2.577; $\mathrm{P}=0.005$ ), tumor capsule (HR, 0.543; CI, 0.316-0.935; $\mathrm{P}=0.027$ ) and tumor embolus (HR, 1.569; CI, $0.976-2.522 ; \mathrm{P}=0.063)$ were positively associated with poor prognosis $(\mathrm{P}<0.05)$. However, no significant association was identified between HCC prognosis and clinicopathological characteristics, including age, gender, tumor differentiation, TNM stage, drinking status, and diameter exhibited $(\mathrm{P}>0.05)$.

miR-125a downregulation is a prognostic marker for survival in patients with HCC. To determine the prognostic value of miR-125a expression in HCC, Kaplan-Meier survival analysis was used to evaluate the association betweenmiR-125a expression, and OS and DFS. The results revealed that low miR-125a expression associated with poor OS, whereas high miR-125a mRNA levels were associated with increased OS. Thus,
reducedmiR-125a expression level was significantly associated with poor OS ( $\mathrm{P}=0.023$; Fig. $3 \mathrm{~A})$ and DFS ( $\mathrm{P}=0.039$; Fig. 3B) in patients with $\mathrm{HCC}$.

Considering that miR-125a expression was positively associated with Ki67 expression $(\mathrm{P}<0.05$; Table I), and miR-125a and Ki67 expression levels exhibited associations with HCC prognosis (Table I and Fig. 3A-D), the prognostic value of miR-125a expression together with Ki67 expression was further investigated. Multivariate analysis of OS and DFS using Kaplan-Meier survival analysis indicated that patients with HCC with low miR-125a expression and high Ki67 expression had significantly decreased OS ( $\mathrm{P}=0.001$; Fig. 3E), and DFS ( $\mathrm{P}=0.003$; Fig. $3 \mathrm{~F})$.

\section{Discussion}

HCC remains one of the most common types of solid tumor malignancy worldwide, with Western Africa and China reporting the highest incidence per capita (16). Management of advanced and metastatic HCC continues to be challenging due to the high expression of drug resistance genes, underlying cirrhosis, and poor liver function in numerous patients (17).

It is now well established that miRNAs serve essential roles in various biological processes, including development, cellular proliferation, apoptosis and oncogenesis $(18,19)$. The role of miRNAs as oncogenes or tumor suppressors in human cancer has been established. Various studies have also begun to elucidate the molecular functional associations between abnormal miRNA expression and the hallmarks of malignant transformation: Aberrant cell growth, cell death, differentiation, angiogenesis, invasion and metastasis (20).

Molecular biomarkers serve an important role in the therapeutic decision making process, as they can be an indicator of the response patients have to individual chemotherapeutic interventions. In HCC, miRNAs exhibit aberrant processing and expression profiles, in addition, the profile of circulating miRNAs is also affected, which renders them potential biomarkers, with possible applications in diagnosis, particularly 
A

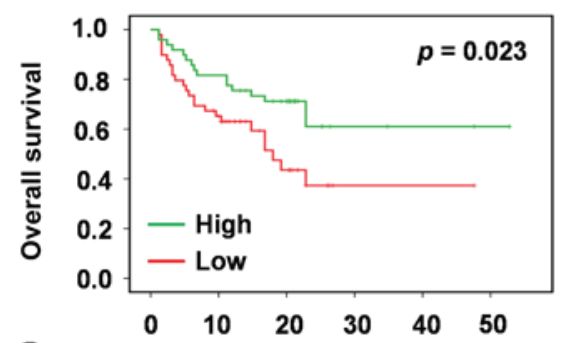

C

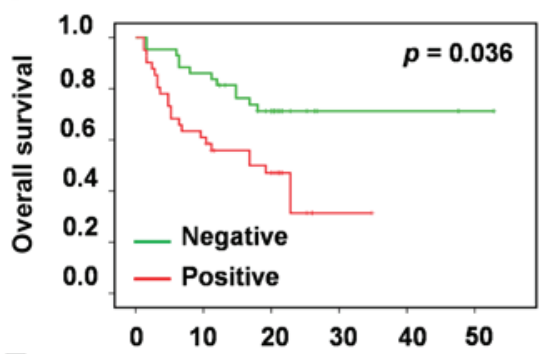

E

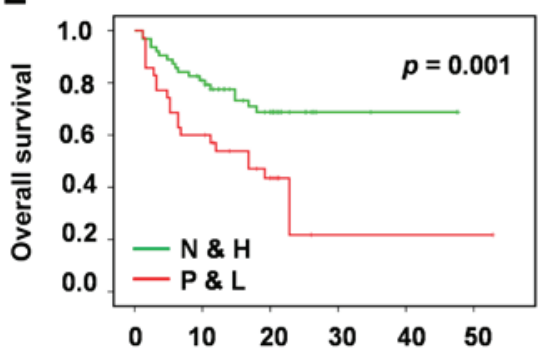

B

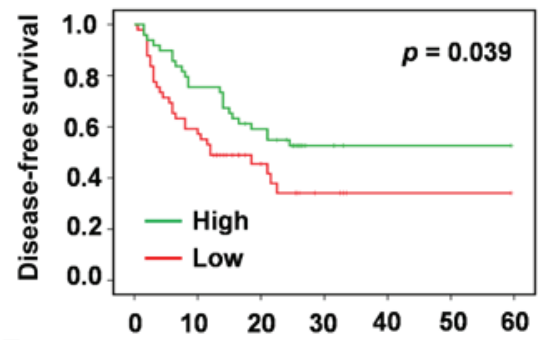

D

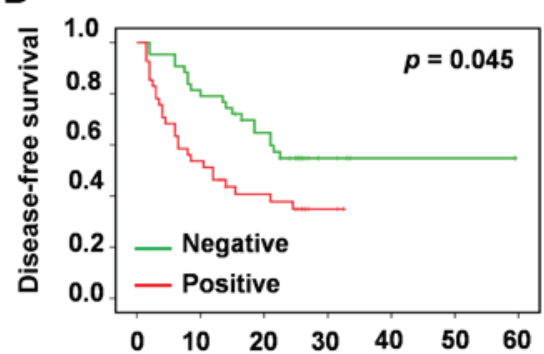

$\mathbf{F}$

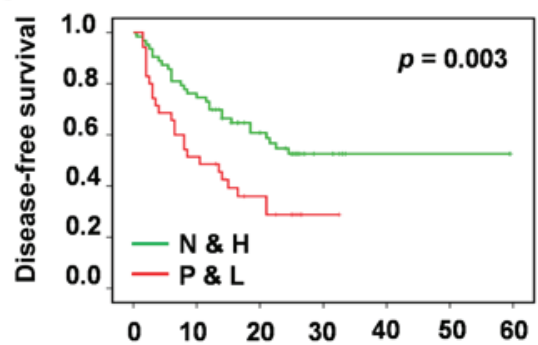

Figure 3. Survival analysis of miR-125a and Ki67 expression in patients with HCC. Univariate survival analysis of (A) OS and (B) DFS in HCC as determined by Kaplan-Meier plots based on miR-125a expression. Univariate survival analysis of (C) OS and (D) DFS in HCC as determined by Kaplan-Meier plots based on Ki67 expression. Multivariate analysis of (E) OS and (F) DFS by Kaplan-Meier survival analysis based on miR-125a, and Ki67 expression. miR, microRNA; OS, overall survival; DFS, disease-free survival; N\&H, Ki67-negative and high miR-125a; P\&L, Ki67-positive and low miR-125a expression.

for early, pre-symptomatic disease, and prognosis of HCC. For instance, research findings collectively demonstrate a tumor suppressor role of miR-188-5p in HCC progression via targeting fibroblast growth factor 5, suggesting that miR-188-5p may serve as a potential prognostic biomarker and therapeutic target for HCC $(21,22)$. The expression of Rho associated coiled-coil containing protein kinase 1 (ROCK1) was decreased significantly following overexpression of miR-335, indicating that ROCK1 is a target gene for miR-335, and miR-335 can inhibit the proliferation and migration invasion of $\mathrm{HCC}$ cells via regulating ROCK1, suggesting that miR-335 may be a therapeutic biomarker of HCC in the future (23).

miR-125a has previously been reported to inhibit breast cancer cell proliferation, invasion and migration (24). Furthermore, miR-125a was validated to prevent the cancer cell invasion in different cancer types, including ovarian (25), glioma (26), gastric (27) and lung cancer (28). miR-125a has been identified to be involved in hepatitis $\mathrm{B}$ virus duplication and the progression of associated liver diseases caused by hepatitis b virus (29). Bi et al (30) investigated a molecular mechanism that has been associated with the tumor-suppressive role of miR-125a. It was demonstrated that miR-125a directly targets matrix metalloproteinase 11 and vascular endothelial growth factor to inhibit the proliferation, and migration of liver cancer cells (30). Tang et al (31) identified that the expression of miR-125a was significantly reduced in highly lung-invasive
HCC-LM3 cells, which suggests that miR-125a may be associated with conferring the invasive and migratory abilities of liver cancer cells. In addition, this suggests that miR-125a may be used as a marker for predicting the prognosis of patients with liver cancer.

In the present study, it was revealed that miR-125a was significantly lower in liver cancer and reduced miR-125a levels in HCC tissues were associated with a shorter overall, and disease-free survival of patients with HCC. In addition, it was demonstrated that miR-125a was a predictor for shorter OS times of patients with HCC. Furthermore, miR-125a expression was significantly negatively associated with alcohol drinking status of patients. Thus, further studies are warranted to investigate the prognostic value of miR-125a in HCC. The evidence presented in the current study and previous studies suggests that miR-125a may function as a tumor suppressor gene in HCC. In addition, there is sufficient evidence indicating that alcoholic beverages are carcinogenic in humans. Therefore, it may be noteworthy to investigate the association between miR-125a expression levels and alcohol consumption in the livers of healthy people, individuals with fatty liver disease, alcoholic hepatitis, alcoholic cirrhosis, or HCC, and to illustrate its possible role and mechanism of miR-125a in alcoholic liver diseases.

miR-125a expression was identified to be negatively associated with Ki67 expression, and miR-125a and Ki67 expression 
levels exhibited associations with HCC prognosis. Notably, patients with HCC with low miR-125a expression and high Ki67expression exhibited significantly decreased OS.

In conclusion, the results of the present study provide the first evidence that reduced miR-125a expression is associated with progression and poor prognosis in patients with $\mathrm{HCC}$. This suggests that miR-125a possesses potential prognostic value as a tumor biomarker for the prognosis of patients with HCC.

\section{Acknowledgements}

The present study was supported by the National Natural Science Foundation of China (grant nos. 81472501, 81201535, 81472202 and 81302065) and Shanghai Health and Family Planning Commission Projects (grant no. 201540228).

\section{References}

1. Ma YS, Wu TM, Lv ZW, Lu GX, Cong XL, Xie RT, Yang HQ Chang ZY, Sun R, Chai L, et al: High expression of miR-105-1 positively correlates with clinical prognosis of hepatocellular carcinoma by targeting oncogene NCOA1. Oncotarget 8 : 11896-11905, 2017.

2. Wu SD, Ma YS, Fang Y, Liu LL, Fu D and Shen XZ: Role of the microenvironment in hepatocellular carcinoma development and progression. Cancer Treat Rev 38: 218-225, 2012.

3. Ching RHH, Sze KMF, Lau EYT, Chiu YT, Lee JMF, Ng IOL and Lee TKW: C-terminal truncated hepatitis B virus $\mathrm{X}$ protein regulates tumorigenicity, self-renewal and drug resistance via STAT3/Nanog signaling pathway. Oncotarget 8: 23507-23516, 2017.

4. Kindrat I, Tryndyak V, de Conti A, Shpyleva S, Mudalige TK, Kobets T, Erstenyuk AM, Beland FA and Pogribny IP MicroRNA-152-mediated dysregulation of hepatic transferrin receptor 1 in liver carcinogenesis. Oncotarget 7: 1276-1287, 2016.

5. Okajima W, Komatsu S, Ichikawa D, Miyamae M, Kawaguchi T, Hirajima S, Ohashi T, Imamura T, Kiuchi J, Arita T, et al: Circulating microRNA profiles in plasma: Identification of miR-224 as a novel diagnostic biomarker in hepatocellular carcinoma independent of hepatic function. Oncotarget 7: 53820-53836, 2016.

6. Zheng H, Zou AE, Saad MA, Wang XQ, Kwok JG, Korrapati A, Li P, Kisseleva T, Wang-Rodriguez J and Ongkeko WM: Alcohol-dysregulated microRNAs in hepatitis B virus-related hepatocellular carcinoma. PLoS One 12: e0178547, 2017.

7. Kutay H, Bai S, Datta J, Motiwala T, Pogribny I, Frankel W, Jacob ST and Ghoshal K: Downregulation of miR-122 in the rodent and human hepatocellular carcinomas. J Cell Biochem 99: 671-678, 2006

8. Tang S, Tan G, Jiang X, Han P, Zhai B, Dong X, Qiao H, Jiang H and Sun X: An artificial lncRNA targeting multiple miRNAs overcomes sorafenib resistance in hepatocellular carcinoma cells. Oncotarget 7: 73257-73269, 2016.

9. Murakami Y, Yasuda T, Saigo K, Urashima T, Toyoda H, Okanoue $\mathrm{T}$ and Shimotohno K: Comprehensive analysis of microRNA expression patterns in hepatocellular carcinoma and non-tumorous tissues. Oncogene 25: 2537-2545, 2006.

10. Shi KQ, Lin Z, Chen XJ, Song M, Wang YQ, Cai YJ, Yang NB, Zheng MH, Dong JZ, Zhang L and Chen YP: Hepatocellular carcinoma associated microRNA expression signature: Integrated bioinformatics analysis, experimental validation and clinical significance. Oncotarget 6: 25093-25108, 2015.

11. Hung CL, Yen CS, Tsai HW, Su YC and Yen CJ: Upregulation of microRNA-19b predicts good prognosis in patients with hepatocellular carcinoma presenting with vascular invasion or multifocal disease. BMC Cancer 15: 665, 2015.

12. Zheng J, Zhou Z, Xu Z, Li G, Dong P, Chen Z, Lin D, Chen B and Yu F: Serum microRNA-125a-5p, a useful biomarker in liver diseases, correlates with disease progression. Mol Med Rep 12: 1584-1590, 2015.
13. Jin L, Zhang Z, Li Y, He T, Hu J, Liu J, Chen M, Gui Y, Chen Y and Lai Y: miR-125b is associated with renal cell carcinoma cell migration, invasion and apoptosis. Oncol Lett 13: 4512-4520, 2017.

14. Edge SB and Compton CC: The American Joint Committee On Cancer: The 7th edition of the AJCC cancer staging manual and the future of TNM. Ann Surg Oncol 17: 1471-1474, 2010.

15. Livak KJ and Schmittgen TD: Analysis of relative gene expression data using real-time quantitative PCR and the 2(-Delta Delta C(T)) method. Methods 25: 402-408, 2001.

16. McGlynn KA, Tsao L, Hsing AW, Devesa SS and Fraumeni JF Jr: International trends and patterns of primary liver cancer. Int J Cancer 94: 290-296, 2001.

17. Dou JP, Yu J, Yang XH, Cheng ZG, Han ZY, Liu FY, Yu XL and Liang P: Outcomes of microwave ablation for hepatocellular carcinoma adjacent to large vessels: A propensity score analysis. Oncotarget 8: 28758-28768, 2017.

18. Chang L, Wang Y, Zhang J and Guo T: The best strategy for HCC patients at each BCLC stage: A network meta-analysis of observational studies. Oncotarget 8: 20418-20427, 2017.

19. Xiang ZL, Zhao XM, Zhang L, Yang P, Fan J, Tang ZY and Zeng ZC: MicroRNA-34a expression levels in serum and intratumoral tissue can predict bone metastasis in patients with hepatocellular carcinoma. Oncotarget 7: 87246-87256, 2016.

20. Gramantieri L, Fornari F, Callegari E, Sabbioni S, Lanza G, Croce CM, Bolondi L and Negrini M: MicroRNA involvement in hepatocellular carcinoma. J Cell Mol Med 12: 2189-2204, 2008.

21. Xue HY, Liu Y, Liao JZ, Lin JS, Li B, Yuan WG, Lee RJ, Li L, $\mathrm{Xu}$ CR and He XX: Gold nanoparticles delivered miR-375 for treatment of hepatocellular carcinoma. Oncotarget 7: 86675-86686, 2016.

22. Fang F, Chang RM, Yu L, Lei X, Xiao S, Yang H and Yang LY: MicroRNA-188-5p suppresses tumor cell proliferation and metastasis by directly targeting FGF5 in hepatocellular carcinoma. J Hepatol 63: 874-885, 2015.

23. Liu H, Li W, Chen C, Pei Y and Long X: miR-335 acts as a potential tumor suppressor miRNA via downregulating ROCK1 expression in hepatocellular carcinoma. Tumor Biol 36: 6313-6319, 2015.

24. Scott GK, Goga A, Bhaumik D, Berger CE, Sullivan CS and Benz CC: Coordinate suppression of ERBB2 and ERBB3 by enforced expression of micro-RNA miR-125a or miR-125b. J Biol Chem 282: 1479-1486, 2007.

25. Cowden Dahl KD, Dahl R, Kruichak JN and Hudson LG: The epidermal growth factor receptor responsive miR-125a represses mesenchymal morphology in ovarian cancer cells. Neoplasia 11: 1208-1215, 2009

26. Cortez MA, Nicoloso MS, Shimizu M, Rossi S, Gopisetty G, Molina JR, Carlotti C Jr, Tirapelli D, Neder L, Brassesco MS, et al: miR-29b and miR-125a regulate podoplanin and suppress invasion in glioblastoma. Genes Chromosomes Cancer 49: 981-990, 2010.

27. Jiang L, Huang Q, Zhang S, Zhang Q, Chang J, Qiu X and Wang E: Hsa-miR-125a-3p and hsa-miR-125a-5p are downregulated in non-small cell lung cancer and have inverse effects on invasion and migration of lung cancer cells. BMC Cancer 10: 318,2010 .

28. Hashiguchi Y, Nishida N, Mimori K, Sudo T, Tanaka F, Shibata K, Ishii H, Mochizuki H, Hase K, Doki Y and Mori M: Down-regulation of miR-125a-3p in human gastric cancer and its clinicopathological significance. Int J Oncol 40: 1477-1482, 2012.

29. Potenza N, Papa U, Mosca N, Zerbini F, Nobile V and Russo A: Human microRNA hsa-miR-125a-5p interferes with expression of hepatitis B virus surface antigen. Nucleic Acids Res 39: 5157-5163, 2011.

30. Bi Q, Tang S, Xia L, Du R, Fan R, Gao L, Jin J, Liang S, Chen Z and $\mathrm{Xu} \mathrm{G}$ : Ectopic expression of miR-125a inhibits the proliferation and metastasis of hepatocellular carcinoma by targeting MMP11 and VEGF. PLoS One 7: e40169, 2012.

31. Tang H, Li RP, Liang P, Zhou YL and Wang GW: miR-125a inhibits the migration and invasion of liver cancer cells via suppression of the PI3K/AKT/mTOR signaling pathway. Oncol Lett 10: 681-686, 2015. 